No. 11(18)

\title{
THE INFLUENCE OF CONSUMER RECOMMENDATIONS ON ADVERTISING STRATEGIES IN A NON-LINEAR OPTIMAL GOODWILL MODEL WITH MARKET SEGMENTATION ${ }^{1}$
}

\author{
Dominika Bogusz, Mariusz Górajski
}

\begin{abstract}
We propose a new dynamical model of product goodwill. It is assumed that the product is sold in many market segments. The segments here are distinct according to the age of the consumers. We take into account the fact that the product goodwill in a segment of new consumers strongly depends on: the level of product goodwill in existing consumer segments, on consumer recommendations, and on advertising efforts which are diverse for different market segments and times. In our optimal control model, the control variables are the company's advertising efforts in order to maximize its profits. The optimal solution of this model is obtained by the use of the maximum principle. Additionally, the sensitivity of this solution to different analytical forms of consumer recommendation functions is briefly analysed.
\end{abstract}

Keywords: goodwill, optimal advertising strategy, consumer recommendations, profit maximization.

JEL Classification: C61, M31, G32, L20.

DOI: $10.15611 / \mathrm{me} .2015 .11 .01$.

\section{Introduction}

Many potential consumers collect information about a product before purchasing it. The main sources of this information are advertisements and consumer recommendations given by people who have already used this product. The traditional way of exchanging information about products is face-to-face communication between acquainted individuals with confidence in each other [Brown, Reingen 1987]. The expansion of the Internet has broadened the opportunity to exchange information about products

\footnotetext{
Dominika Bogusz, Mariusz Górajski

Department of Econometrics, University of Łódź

dominika.bogusz@uni.lodz.pl,mariuszg@math.uni.lodz.pl

${ }^{1}$ The authors gratefully acknowledge financial support from the National Science Centre in Poland. Decision number: DEC-2011/03/D/HS4/04269.
} 
on websites, blogs, chatrooms, or emails [Hennig-Thurau et al. 2004]. Therefore, access to information and the possibility of comparing information is growing. Thus the use of consumer recommendations has become less time consuming and more common [Peterson, Merino 2003] in comparison to traditional sources of recommendations. Empirical research indicates that the consumer recommendations transferred by traditional or electronic channels have a strong influence on consumer choices [Gupta, Harris 2010]. They are more important than advertising in raising the awareness of an innovation, and this causes the consumers to feel more secure in deciding about new unknown products [Sheth 1971]. Consumer recommendations also provide the possibility of changing a negative or neutral opinion about a product to a positive one. The effect of these possibilities is much stronger than the impact of advertising [Day 1971].

Thus recommendations are an important tool for making purchasing decisions by consumers and, therefore, companies wishing to increase sales may need to develop strategies for encouraging the sharing of opinion about their products between consumers [Hennig-Thurau et al. 2004]. One of the tools enabling a company to affect consumer recommendations may be advertising [Bayus 1985; East et al. 2005].

In this paper, we investigate a new model of product goodwill in which consumer recommendations and advertising efforts play crucial roles. Product goodwill is defined as the part of the demand which results from the company's investment in advertising. It is a fundamental feature that determines survival and effectiveness on the market. The first model describing the dynamics of product goodwill was investigated by [Nerlove, Arrow 1962]. In the classical model, the level of product goodwill depends on its depreciation rate and on investment in advertising. This model has been extended by many scholars. The results of their studies have been reviewed by Feichtinger et al. [1994] and Huang et al. [2012]. Recently, based on the observation that one of the basic marketing strategies designed to stimulate product goodwill is market segmentation, cf. [Wyner 2002; Kotler, Keller 2006], scholars have started to consider models of goodwill which include market segmentation. Buratto et al. have considered a dynamic goodwill model with a finite number of market segments, which are distinguished by the age of the consumers [Buratto et al. 2006]. Grosset and Viscolani have expanded the classical model to markets with infinitely many market segments [Grosset, Viscolani 2005]. They assumed that the level of goodwill in the initial segment is equal to 0 . 
In our new model, we assume that the market is divided into infinitely many segments with respect to consumer age. The level of product goodwill depends on its depreciation rate and advertising efforts. The novelty in this model is that the perceived level of product goodwill among new consumers depends on the level of product goodwill in the existing consumer segments, on consumer recommendations, and on advertising efforts which are diverse for the different market segments and time. Moreover, as far as we know, for the first time in this type of model, non-linear advertising efforts are considered.

The aim of this paper is to study the deep connections between agespecific segmentation, product goodwill, advertising efforts, and consumer recommendations. This paper is organized as follows. In Section 2 we describe the model and introduce the mathematical formulation of the consumer recommendation function. In Section 3 we derive formulas for the optimal advertising strategies. Finally, in Section 4 we numerically obtain an optimal solution and present some numerical simulations which explicitly show the effect of different shapes of recommendation function on the optimal advertising efforts, optimal level of product goodwill, and the company's profit.

\section{Optimal Model of Goodwill}

\subsection{Goodwill dynamics}

Consider a company selling a product on a market in which there are infinitely many different segments defined by the age of consumer $a$. We assume that if consumers are satisfied with their purchase of the product, then a repetition of the purchase of the product follows. Furthermore, we assume that the age of consumers is normalized to the interval $[0,1]$, thus the minimum and maximum consumer age are equal to 0 and 1 , respectively, and the duration of the product life cycle is equal to $T$. In each segment $a$ and at each moment of time $\mathrm{t} \in[0, \mathrm{~T}]$ we model the product goodwill $G(t, a)$ defined in [Nerlove, Arrow 1962] as the part of the product demand that results from investments in advertising. We assume that the demand function $q$ takes the form

$$
q(p, G)=(p(t))^{-\xi} G(t, a),
$$

where $p(t)$ is the price of the product and the non-negative $\xi$ is the price elasticity of demand. 
The company can stimulate the different levels of product goodwill by advertising efforts. Moreover, according to [Allenby, Rossi 1999], advertising strategies should be adapted to the specific market segments. Targeted marketing is considered to be the most effective and to carry the greatest benefit in comparison with other forms of marketing. Very extensive psychological studies have been conducted on the effects of advertising on various sectors of society. The differences are perceived in many ways, not least in shaping the advertising response of younger and older consumers (such research can be found in [Whissell, McCall 1997; Rovinelli, Whissell 1998; Drolet et al. 2007]). We denote by $u(t, a)$ and $v(t)$ the advertising strategy at time $t$ directed to consumer segment $a$, and to new consumers, respectively. In our model, we assume that $u(t, a)$ and $v(t)$ have a positive influence on the rate of change of the product goodwill $G(t, a)$ and on the level of the product goodwill for new consumers, respectively.

For many years, empirical studies have contradicted the linearity of the advertising response function ${ }^{2}$. The authors in [Simon, Arndt 1980], have provided over 100 experimental and real evidence studies and they conclude that advertising has diminishing returns to scale. Therefore, we take into account this proposal and assume in our model that advertising efforts have a non-linear-concave effect on the rate of change of the product goodwill. Similar conclusions have been obtained by Taylor in [Taylor et al. 2009].

Summarizing the above deliberations, we consider the following dynamic model of product goodwill:

$$
\left\{\begin{array}{l}
\frac{\partial G(t, a)}{\partial t}+\frac{\partial G(t, a)}{\partial a}+\delta G(t, a)=u^{\rho}(t, a), \quad(t, a) \in[0, T] \times[0,1], \\
G(t, 0)=\int_{0}^{1} b(t, a) G(t, a) d a+v^{\rho}(t), \quad t \in[0, T], \\
G(0, a)=G_{p}(a), \quad a \in[0,1] .
\end{array}\right.
$$

In this model,

$G(t, a)$ is the product goodwill at time $t$ for consumer segment $a$, $u(t, a)$ is the advertising effort at time $t$ directed to consumer segment $a$, $v(t)$ is the advertising effort directed to new consumers at time $t$,

\footnotetext{
${ }^{2}$ An advertising response function is the relationship between an input of advertising efforts and its effect on demand [Simon, Arndt 1980].
} 
$\rho \in(0,1]$ is the advertising elasticity of instantaneous rate of change of goodwill;

$r(a)$ is the rate of consumer recommendations about product quality in consumer segment $a$,

$\delta$ is the depreciation rate of product goodwill,

$b(t, a)=(1+r(a))\left(1+\frac{u^{\rho}(t, a)}{G(t, a)}\right)-1$ is the total rate of consumer

recommendations as the effect of the accumulation of the consumer recommendations rate of product quality $r$ and the rate of current advertising efforts pointed at existing consumers $\frac{u^{\rho}(t, a)}{G(t, a)}$.

Buttler has pointed out that consumer recommendations can operate as an important source of information for consumers who are not familiar with the product [Buttler 1998]. Moreover, the authors (see: [Herr et al. 1991]) have observed that consumers usually remember the information provided by other consumers for a long time. However, the impact of consumer recommendation on purchase behaviour decreases when consumers possess information from other sources, e.g. from their own experience. This directly follows from the fact that the consumers has greater trust in their own opinions than in the opinions of others. Furthermore, consumer behaviour associated with providing recommendations varies markedly in different market segments [East et al. 2005]. Therefore, in our model, the total consumer recommendations $b$ only affect the decisions of new consumers, which is described by the boundary condition in (1):

$$
G(t, 0)=\int_{0}^{1} b(t, a) G(t, a) d a+v^{\rho}(t) .
$$

We also assume that consumer recommendations are varied according to the segment of the market and their force is enhanced by an advertising effort $u(t, a)$.

\subsection{Company goals}

The company goal consists of choosing the advertising strategy to maximize its profits. We denote the instantaneous cost of advertising efforts in segment $a \in(0,1]$ by

$$
C_{1}(u)=\beta u^{2}(t, a)
$$

where $\beta>0$ is the unit price of advertising efforts. From (2) it follows that 
advertising efforts posses decreasing returns to scale (i.e. $\frac{\partial^{2} C_{1}}{\partial u^{2}}>0$ ). In a similar way, we define the cost of advertising efforts in the segment of new consumers:

$$
C_{2}(v)=\beta v^{2}(t)
$$

The goal functional for the firm takes the form

$$
\begin{gathered}
J(G, u, v)=\int_{0}^{1} \int_{0}^{T}\left(q(p(t, a), G(t, a))(p(t)-c(t))-C_{1}(u)-C_{2}(v)\right) d t d a= \\
=\int_{0}^{1} \int_{0}^{T}\left(\alpha(t) G(t, a)-\beta u^{2}(t, a)-\beta v^{2}(t)\right) d t d a,
\end{gathered}
$$

where $c(t)$ is the unit product cost, $\alpha(t)=p(t)^{-\xi}(p(t)-c(t))$ and $\alpha(t) G(t, a)$ is the company profit from the sale of goods in unit time at moment $t$ in segment $a$. Assume that the sets of admissible controls $u$ and $v$ have the forms

$$
\begin{gathered}
U_{a d}=\left\{u \in L^{\infty}((0, T) \times(0,1)): u(t, a) \geq 0 \text { for a.a. }(t, a) \in[0, T] \times[0,1]\right\} \\
V_{a d}=\left\{v \in L^{\infty}(0, T): v(t) \geq 0 \text { for a.a. } t \in[0, T]\right\} .
\end{gathered}
$$

Definition 1. The pair $\left(G^{*}, u^{*}, v^{*}\right)$ is an optimal solution for problem (1) and (4) if $\left(u^{*}, v^{*}\right) \in U_{a d} \times V_{a d}$ and $G^{*}$ satisfies the equation (1) with $u=u^{*}$ and $v=v^{*}$, and $J\left(G^{*}, u^{*}, v^{*}\right) \geq J(G, u, v)$ for any admissible controls $(u, v)$ for which $G$ satisfies the equation (1).

Moreover, we assume that

A1. $r:[0,1] \rightarrow[0, \infty)$ is a continuous function such that

$$
\int_{0}^{1} r(a) \exp (-\delta a) d a<1 .
$$

A2. the controls $u:[0, T] \times[0,1] \rightarrow[0, \infty)$ and $v:[0, T] \rightarrow[0, \infty)$ are measurable and bounded functions.

Remark 1. The existence and uniqueness of an optimal solution to (1) and (4) under the assumptions A1.-A2. was established in [Bogusz, Górajski 2014].

\subsection{Necessary conditions for optimal advertising polices}

Let $\left(G^{*}, u^{*}, v^{*}\right)$ be the optimal solution for problem (1) and (4). In this section we give the conditions which are satisfied by the optimal solution. 
First, we introduce the adjoint system for problem (1) and (4). Consider a function $\xi:[0, T] \times[0,1] \rightarrow \mathbb{R}$ which satisfies the equations

$$
\begin{cases}\frac{\partial \xi(t, a)}{\partial t}+\frac{\partial \xi(t, a)}{\partial a}=\alpha(t)+\xi(t, a) \delta-\xi(t, 0) r(a) & (t, a) \in[0, T] \times[0,1] \\ \xi(T, a)=0 & a \in[0,1] \\ \xi(t, 1)=0 & t \in[0, T]\end{cases}
$$

We call $\xi$ the adjoint function for $G^{*}$ and we call problem (6) the adjoint system for (1), (4). In [Feichtinger et al. 2003] it is proven that there exists a unique solution to the adjoint system (6).

For the optimal solution $\left(G^{*}, u^{*}, v^{*}\right)$ and the corresponding adjoint function $\xi$, we define the boundary and distributed Hamiltonians. The Hamiltonian associated with the boundary condition can be written as

$$
\begin{gathered}
H_{b}(t, v)=\xi(t, 0)\left(\int_{0}^{1} b(t, a) G(t, a) d a+v^{\rho}(t)\right)- \\
\int_{0}^{1}\left(\alpha(t) G(t, a)-\beta u^{2}(t, a)\right) d a+\beta v^{2}(t) .
\end{gathered}
$$

The distributed Hamiltonian takes the form

$$
\begin{gathered}
H(t, a, u)=-\alpha(t) G(t, a)+\beta u^{2}(t, a)+\beta v^{2}(t)+ \\
\xi(t, a)\left(-\delta G(t, a)+u^{\rho}(t, a)\right)+\xi(t, 0) b(t, a) G(t, a) .
\end{gathered}
$$

Based on the maximum principle introduced by [Feichtinger et al. 2003], we obtain the conditions

$$
\begin{gathered}
\frac{\partial H_{b}(t, v)}{\partial v}=\rho\left(v^{*}(t)\right)^{\rho-1} \xi(t, 0)+2 \beta v^{*}(t)=0 \\
\frac{\partial H(t, v)}{\partial u}=2 \beta u^{*}(t, a)+\rho\left(u^{*}(t, a)\right)^{\rho-1}(\xi(t, a)+\xi(t, 0)(1+r(a)))=0 .
\end{gathered}
$$

Hence,

and consequently

$$
v^{*}(t)=\left(-\frac{\rho \xi(t, 0)}{2 \beta}\right)^{\frac{1}{2-\rho}}
$$

$$
u^{*}(t, a)=\left(\frac{-\rho(\xi(t, a)+\xi(t, 0)(1+r(a)))}{2 \beta}\right)^{\frac{1}{2-\rho}}
$$


Summarizing the above considerations, the optimal path $\left(G^{*}, u^{*}, v^{*}\right)$ is the solution of the system

$$
\left\{\begin{array}{l}
\frac{\partial G^{*}(t, a)}{\partial t}+\frac{\partial G^{*}(t, a)}{\partial a}+\delta G^{*}(t, a)=\left(u^{*}(t, a)\right)^{\rho} \quad(t, a) \in[0, T] \times[0,1], \\
G^{*}(t, 0)=\int_{0}^{1} b(t, a) G^{*}(t, a) d a+\left(v^{*}(t)\right)^{\rho} \quad t \in[0, T], \\
G^{*}(0, a)=G_{p}(a) \quad a \in[0,1] \\
\frac{\partial \xi(t, a)}{\partial t}+\frac{\partial \xi(t, a)}{\partial a}=\alpha(t)+\xi(t, a) \delta-\xi(t, 0) r(a)(t, a) \in[0, T] \times[0,1], \\
\xi(T, a)=0 \quad a \in[0,1], \\
\xi(t, 1)=0 \quad t \in[0, T], \\
v^{*}(t)=\left(-\frac{\rho \xi(t, 0)}{2 \beta}\right)^{\frac{1}{2-\rho}} \quad(t, a) \in[0, T] \times[0,1], \\
u^{*}(t, a)=\left(\frac{-\rho(\xi(t, a)+\xi(t, 0)(1+r(a)))}{2 \beta}\right)^{\frac{1}{2-\rho}} \quad(t, a) \in[0, T] \times[0,1] .
\end{array}\right.
$$

The system (7) does not possess an analytical solution. The method of the numerical solution of (7) has been described in [Bogusz, Górajski 2014].

\section{Simulation of the goodwill model}

In this section we analyse how the shape of the recommendation function $r$ determines the optimal advertising strategy.

Based on empirical evidence, Hennig-Thurau et al. [2004] have found that each market may have a different recommendation function. Thus, while considering the advertising strategy, it is crucial to focus it on the group of consumers (market segments) which has the strongest influence on the decisions of new consumers. Therefore we consider three scenarios. In the first scenario, we assume that the older consumers have the strongest influence on new consumers. This means that the new consumer takes more into consideration the judgements of older consumers on the product quality than the judgements of the younger ones. Thus, we assume that the recommendation function $r$ is increasing and linear with respect to consumer age. In the second scenario, we assume that younger consumers 
have the strongest impact on new consumers, hence the recommendation function is linear and decreasing. In the last scenario, we consider a situation where middle aged consumers have the strongest influence on the new buyers. Thus the recommendation function is concave and takes its maximum value at $a=0.5$.

Summarizing, we analyse model (1), (4) with the three different shapes of consumer recommendation functions which are described in Table 1.

Table 1. Shapes of consumer recommendation functions for $a \in[0,1]$

\begin{tabular}{|c|c|}
\hline Recommendation function & Shape \\
\hline$r(a)=0.1+0.8 a$ & linearly increasing \\
\hline$r(a)=0.9-0.8 a$ & linearly decreasing \\
\hline$r(a)=-2 a^{2}+2 a+0.17$ & concave \\
\hline
\end{tabular}

Source: own computations.

All the functions proposed in Table 1 correspond to situations in which consumers of different ages have positive opinions about the product. We assume that

$$
\int_{0}^{1} r(a) d a=0.5,
$$

which means that the cumulative effects of recommendations are equal for these functions. Moreover, this condition expresses that the average level of positive judgements by consumers is approximately $50 \%$.

In the simulations, we assume that the initial level of goodwill is constant with respect to market segments, i.e. $G_{p}(a)=1, a \in[0,1]$. We take into account three lengths of product life cycle: $T=0.5, T=1, T=1.5$. This reflects the situation where the product lives for a shorter time than the maximum age of the potential consumer (in the first case), is the same (in the second), or lives longer than the age of the potential consumers (third case). We also set constant the depreciation rate of product goodwill $\delta=0.3$, which means that in each market segment, $30 \%$ of the product goodwill vanishes. We presuppose that the unit price of advertising efforts $\beta=0.01$, and $\alpha(t)=1$.

We start this analysis with showing the goodwill trajectory (see Figure 1) and the value of the goal functional (see Table 2) in the case where there is no advertising effort and $r$ is linear and decreasing with respect to consumer age $^{3}$.

\footnotetext{
${ }^{3}$ Similar results can be obtained for a linearly increasing $r$ or for a concave $r$.
} 


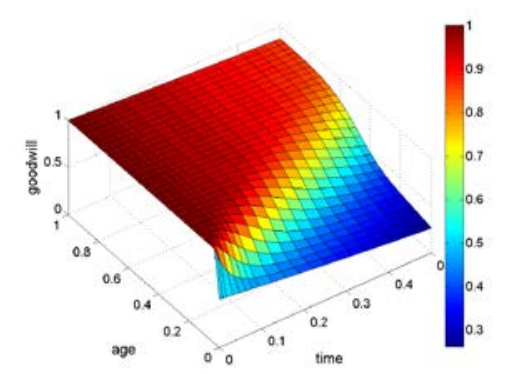

Fig. 1. The goodwill paths in the model (1), (4) without advertising effort, $T=0.5$

Source: own computations.

It may be noted that the goodwill paths are diminishing over time and their rate of change is higher for young consumers than for old consumers. This is consistent with assumption (5). Therefore the rate of consumer recommendations at an average level of $50 \%$ (cf. (1)) is not sufficient to ensure a constant level of product goodwill.

The total profits of a firm in models with different consumer recommendation functions $r$ and different durations of the product life cycle $T$ are presented in Table 2.

Table 2. The values of the goal functional (4) for models (1) without advertising efforts

\begin{tabular}{|l|c|c|c|}
\hline \multicolumn{1}{|c|}{$r$} & $T=0.5$ & $T=1$ & $T=1.5$ \\
\hline Linearly increasing & 0.385 & 0.639 & 0.777 \\
\hline Linearly decreasing & 0.382 & 0.608 & 0.706 \\
\hline Concave & 0.384 & 0.623 & 0.730 \\
\hline
\end{tabular}

Source: own computations.

The values of the goal functional $J$ for models with $T=0.5$ and different shapes of function $r$ are similar to each other; significant differences are obtained for a longer period of the product life cycle. The goal functional takes the greatest value when the recommendation function $r$ is linearly increasing, the smallest value is obtained for $r$ linearly decreasing. This means that when there is no advertising effort, positive opinions among older consumers have a stronger influence on the growth of the company's profit than positive opinions in the group of younger consumers. It is worth mentioning that the extension of the product life cycle has a positive effect on the value of the goal functional $J$ for every shape of recommendation function and the growth of $J$ with respect to the 
duration of the product life cycle is concave. This means that one cannot expect that the growth of firm's profits is proportional to the length of the product life cycle, e.g. doubling the product life cycle does not double the firm's profit.

(1)

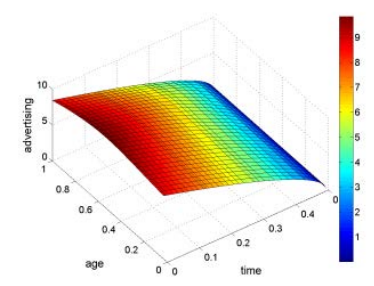

(4)

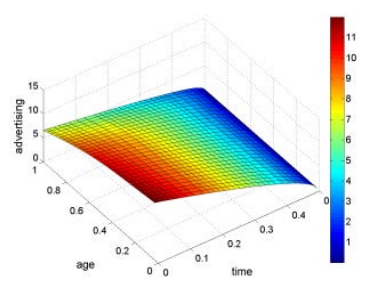

(7)

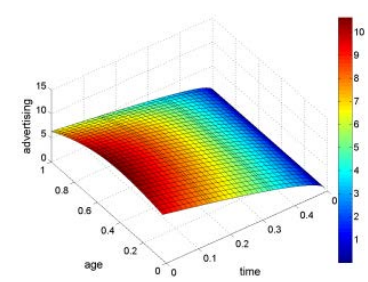

(2)

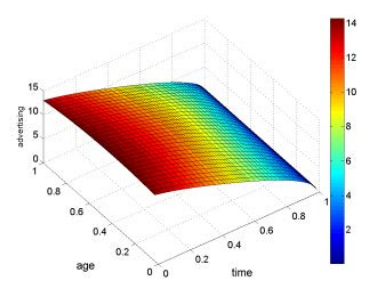

(5)

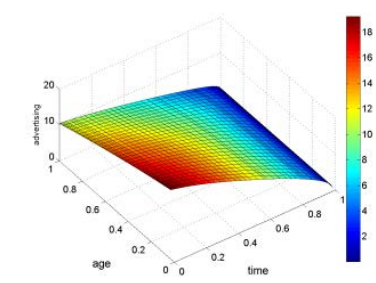

(8)

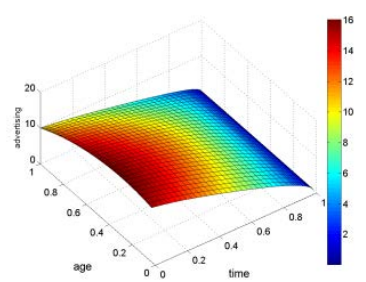

(3)

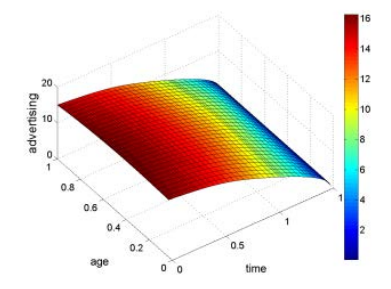

(6)

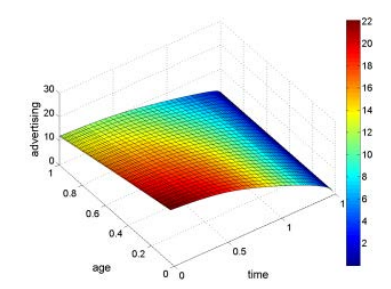

(9)

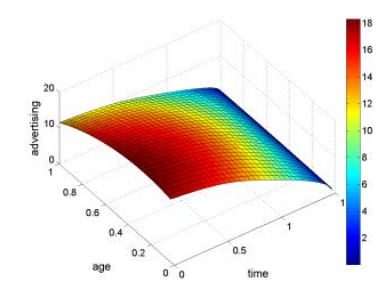

Fig. 2. The optimal advertising strategies for existing consumers in the model with:

(1) linearly increasing $r$ and $T=0.5$, (2) linearly increasing $r$ and $T=1$,

(3) linearly increasing $r$ and $T=1.5$, (4) linearly decreasing $r$ and $T=0.5$,

(5) linearly decreasing $r$ and $T=1$, (6) linearly decreasing $r$ and $T=1.5$,

(7) concave $r$ and $T=0.5$, (8) concave $r$ and $T=1$, (9) concave $\mathrm{r}$ and $T=1.5$

Source: own computations.

Figure 2 presents the optimal advertising efforts for existing consumers $u$ in models with different recommendation functions $r$ and different durations of the product life cycle $T$. Each of the optimal strategies takes the highest values at the beginning of the considered period, and decreases over time. Changing the shape of the recommendation function changes the optimal strategy. For the model with a decreasing linear function $r$ (see 
Figures 2.4-2.6), the optimal advertising strategy takes the largest values among the youngest consumers, whereas in the model with linearly increasing recommendation function (see Figures 2.1-2.3), the advertising efforts are almost constant over all consumers (except in the most extreme segments). For the model with $r$ concave, the advertising efforts are directed most intensely at the first half of the age segments. The highest level of advertising efforts is obtained for the model with a linearly decreasing function $r$.

(1)

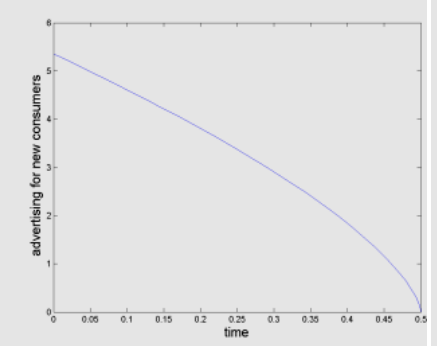

(4)

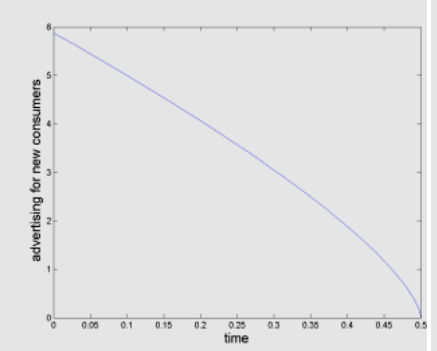

(7)

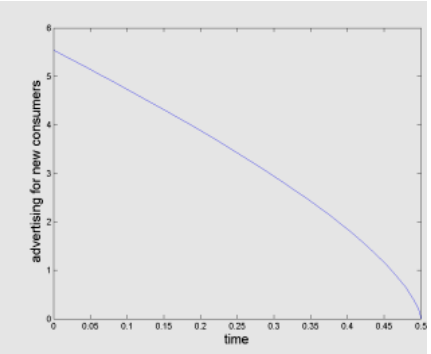

(2)

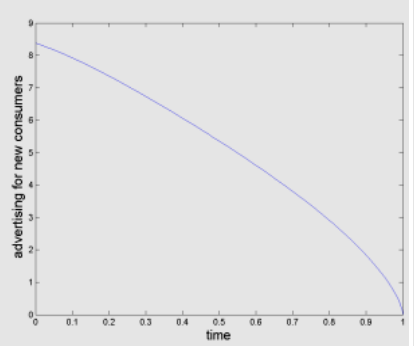

(5)

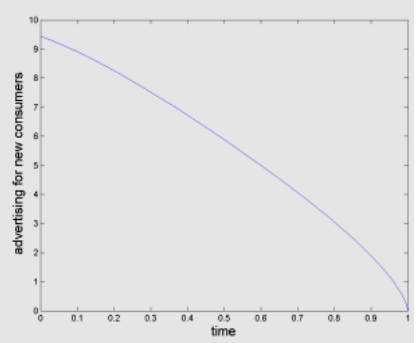

(8)

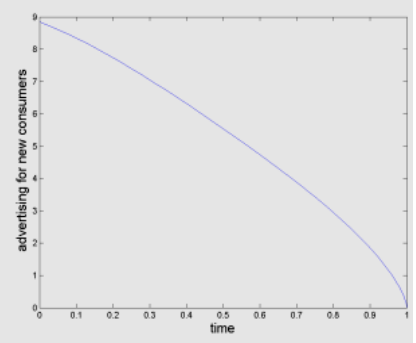

(3)

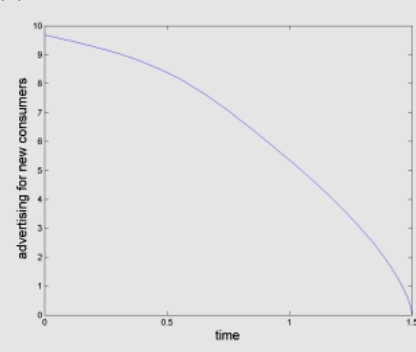

(6)

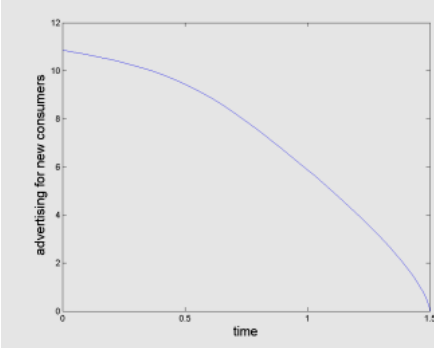

(9)

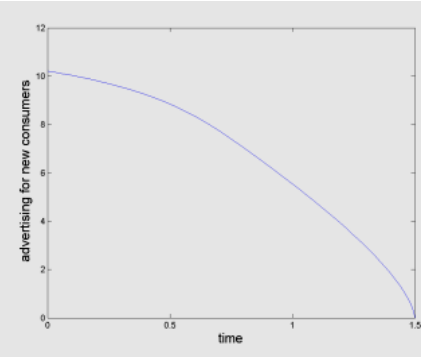

Fig. 3. The optimal advertising strategies for new consumers in the model with

(1) linearly increasing $r$ and $T=0.5$, (2) linearly increasing $r$ and $T=1$,

(3) linearly increasing $r$ and $T=1.5$, (4) linearly decreasing $r$ and $T=0.5$,

(5) linearly decreasing $r$ and $T=1$, (6) linearly decreasing $r$ and $T=1.5$,

(7) concave $r$ and $T=0.5$, (8) concave $r$ and $T=1$, (9) concave $r$ and $T=1.5$

Source: own computations. 
One can also notice that an increase in the duration of the product life cycle causes the optimal advertising strategies to take higher values in the initial period for each shape of the consumer recommendation functions, when compared to models with shorter $T$.

The optimal advertising strategies for new consumers $v$ (see Figure 3) have very similar concave shapes for all the models considered. Each strategy decreases over time. The highest value of $v$ is obtained for the model with a linearly decreasing consumer recommendation function, the smallest value of $v$ is obtained in the model with a linearly increasing $r$. Similarly to the optimal advertising strategies for existing consumers, the maximum levels of the optimal advertising strategies for new consumers increase with a longer product life cycle.

(1)

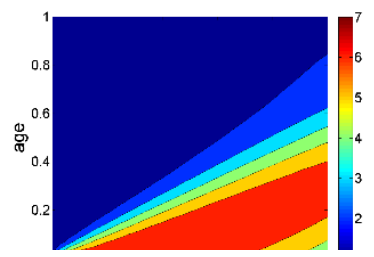

(4)

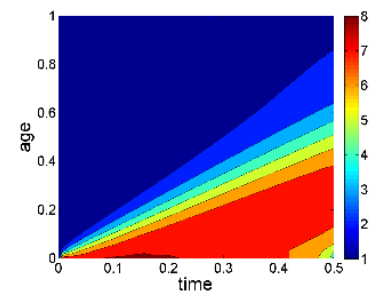

(7)

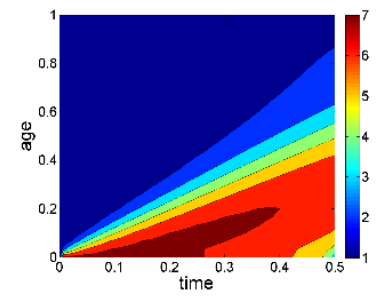

(2)

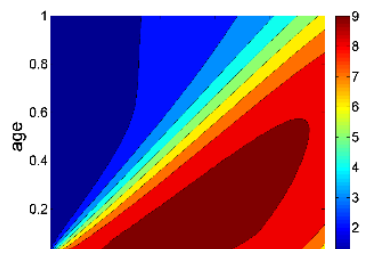

(5)

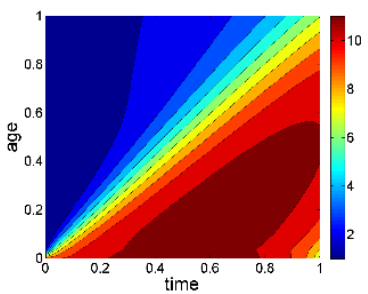

(8)

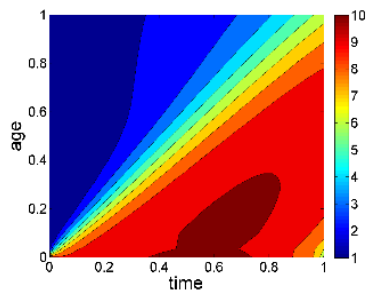

(3)

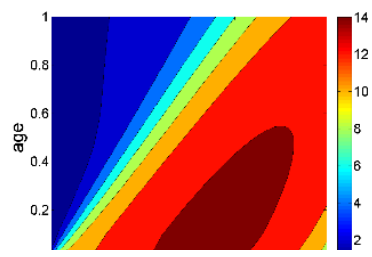

(6)

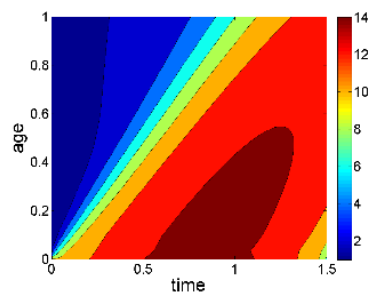

(9)

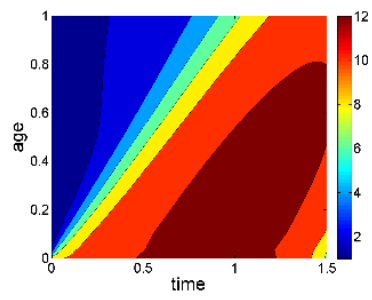

Fig. 4. The optimal goodwill path in the model with

(1) linearly increasing $r$ and $T=0.5$, (2) linearly increasing $r$ and $T=1$,

(3) linearly increasing $r$ and $T=1.5$, (4) linearly decreasing $r$ and $T=0.5$,

(5) linearly decreasing $r$ and $T=1$, (6) linearly decreasing $r$ and $T=1.5$,

(7) concave $r$ and $T=0.5$, (8) concave $r$ and $T=1$, (9) concave $r$ and $T=1.5$

Source: own computations. 
In order to maximize the firm's profit, one should choose the advertising strategies in which the greatest effort is employed at the beginning of the period considered, and diminishes over time. The choice of the consumer segments in which one should make the biggest advertising efforts strongly depends on consumers' positive judgement of the product in the various market segments.

The optimal paths of product goodwill $G$ (see Figure 4) for each shape of the consumer recommendation function are non-decreasing, which is in contrast with the trajectories of the product goodwill without advertising effort (see Figure 1). $G$ reaches its maximum value for young consumers, and these values spread to older consumers with time. Therefore, if the duration of the product life cycle is longer, then the product goodwill takes on higher values for a larger number of segments. Moreover, the maximum level of goodwill is obtained at different times for different shapes of recommendation functions.

The biggest differences between the models can be seen in the value of the goal functional (see Table 3).

Table 3. The values of the goal functional (4) for the optimal advertising strategy in the non-linear model with $\rho=0.5$

\begin{tabular}{|c|c|c|c|}
\hline$r(a)$ & $T=0.5$ & $T=1$ & $T=1.5$ \\
\hline Linearly increasing & 1.39 & 4.87 & 9.48 \\
\hline Linearly decreasing & 1.62 & 5.67 & 11.90 \\
\hline Concave & 1.46 & 5.18 & 10.58 \\
\hline
\end{tabular}

Source: own computations.

Applying the optimal advertising strategy significantly increases the value of the goal functional $J$. The highest value is obtained for the model with a linearly decreasing function $r$, whereas the lowest is for the model with a linearly increasing function $r$. The values of $J$ are increasing and convex as a function of the duration of the product life cycle. These properties mean that, e.g. doubling the product life cycle more than doubles the firm's profit.

Table 4. The values of the goal functional for the optimal advertising strategy in the linear model with $\rho=1$

\begin{tabular}{|c|c|c|c|}
\hline$r(a)$ & $T=0.5$ & $T=1$ & $T=1.5$ \\
\hline Linearly increasing & 4.78 & 23.19 & 105.56 \\
\hline Linearly decreasing & 5.75 & 44.93 & 152.75 \\
\hline Concave & 4.49 & 24.88 & 110.05 \\
\hline
\end{tabular}

Source: own computations. 
Finally, the goal functional for the non-linear model (1), (4) $(\rho=0.5)$ is juxtaposed with the results obtained for the linear model (1), (4) $((\rho=1)$ and presented in Table 4.

Taking into account the non-linearities in the model (1), (4) reduces the total profits of the company compared with the linear model. At the same time, the trend is maintained that the company has the greatest profit when the product is well regarded by young consumers and the lowest profit is obtained when only the oldest consumers have a positive opinion about the product.

\section{Conclusions}

We have developed a new dynamical optimal control model of product goodwill with advertising effort and consumer recommendations. We introduced a mathematical formulation of positive consumer judgements about a product. This notion affects the size and shape of the optimal advertising strategy. Therefore one should take into account the diversity between various segments of consumers, because identifying those consumer segments in which the product is evaluated positively can significantly affect the company's profit. It is also a crucial conclusion from our research that consumer recommendations themselves are not a sufficient tool for keeping product goodwill at a constant level, and it is necessary to strengthen them by advertising efforts.

It is important to draw attention to the duration of the product life cycle because its length significantly increases the firm's profits.

Due to the fact that the differences in income levels are so high between the linear and non-linear models, it is important to conduct further research on the shape of the response advertising function and include this in the creation of advertising strategies.

\section{References}

Allenby G., Rossi P. (1999). Marketing models of consumer heterogeneity. Journal of Econometrics. Vol. 89. No. 1-2. Pp. 57-78.

Bogusz D., Górajski M. (2014). Optimal boundary control problem for a PDE model of goodwill dynamic. arXiv preprint arXiv:14110880.

Bayus B. (1985). Word of mouth: the indirect effects of marketing efforts. Journal of Advertising Research. Vol. 25. No. 3. Pp. 31-39.

Brown J., Reingen P. (1987). Social ties and word-of-mouth referral behavior. Journal of Consumer Research. Vol. 3. Pp. 350-362.

Buratto A., Grosset L.,Viscolani B. (2006). Advertising a new product in a segmented market. European Journal of Operational Research. Vol. 175. No. 2. Pp. 1262-1267. 
Buttle F. (1998). Word of mouth: understanding and managing referral marketing. Journal of strategic marketing. Vol. 6. No. 3. Pp. 241-254.

Day G.S. (1971). Attitude change, media and word of mouth. Journal of Advertising Research. Vol. 11. No. 6. Pp. 31-40.

Drolet A., Williams P., Lau-Gesk L. (2007). Age-related differences in responses to affective vs. rational ads for hedonic vs. utilitarian products. Marketing Letters. Vol. 18. No. 4. Pp. 211-221.

East R., Hammond K., Lomax W., Robinson H. (2005). What is the effect of a recommendation? The Marketing Review. Vol. 5. No. 2. Pp. 145-157.

Feichtinger G., Hartl R., Sethi S. (1994). Dynamic optimal control models in advertising: Recent development. Management Science. Vol. 40. No. 2. Pp. 195-226.

Feichtinger G., Tragler G., Veliov V. (2003). Optimality conditions for age-structured control systems. Journal of Mathematical Analysis and Applications. Vol. 288. No. 1. Pp. 47-68.

Grosset L., Viscolani B. (2005). Advertising for the introduction of an age-sensitive product. Optimal Control Applicattions and Methods. Vol. 26. No. 3. Pp. 157-167.

Gupta P., Harris J. (2010). How e-wom recommendations influence product consideration and quality of choice: A motivation to process information perspective. Journal of Business Research. Vol. 63. No. 9. Pp. 1041-1049.

Hennig-Thurau T., Gwinner K., Walsh G., Gremler D. (2004). Electronic word-of-mouth via consumer-opinion platforms: What motivates consumers to articulate themselves on the internet? Journal of Interactive Marketing. Vol. 18. No. 1. Pp. 38-52.

Herr P., Kardes F., Kim J. (1991). Effects of word-of-mouth and product-attribute information on persuasion: An accessibility-diagnosticity perspective. Journal of Consumer Research. Vol. 14. No. 4. Pp. 454-462.

Huang J., Leng M., Liang L. (2012). Recent developments in dynamic advertising research. European Journal of Operational Research. Vol. 220. No. 3. Pp. 591-609.

Kotler P., Keller K. (2006). Marketing Management. Twelfth Edition. Pearson Prentice Hall. New Jersey.

Nerlove M., Arrow J. (1962). Optimal advertising policy under dynamic conditions. Economica. Vol. 29. No. 114. Pp. 129-142.

Peterson R., Merino M. (2003). Consumer information search behavior and the internet. Psychology and Marketing. Vol. 20. No. 2. Pp. 99-121.

Rovinelli L., Whissell C. (1998). Emotion and style in 30-second television advertisements targeted at men, women, boys, and girls. Perceptual and Motor Skills. Vol. 86. No. 3. Pp. 1048-1050.

Sheth J. (1971). Word-of-mouth in low-risk innovations. Journal of Advertising Research. Vol. 11. No. 3. Pp. 15-18.

Simon J., Arndt J. (1980). The shape of the advertising response function. Journal of Advertising Research. Vol. 20. No. 4. Pp. 11-28.

Taylor J., Kennedy R., Sharp B. (2009). Is once really enough? Making generalizations about advertising's convex sales response function. Journal of Advertising Research. Vol. 49. No. 2. Pp. 198-200.

Whissell C., McCall L. (1997). Pleasantness, activation, and sex differences in advertising. Psychological reports. Vol. 81. No. 2. Pp. 355-367.

Wyner G. (2002). Segmentation architecture. Marketing Management. Vol. 11. No. 2. Pp. 6-7. 